\title{
p38 Mitogen-Activated Protein Kinase Is Activated after a Spinal Nerve Ligation in Spinal Cord Microglia and Dorsal Root Ganglion Neurons and Contributes to the Generation of Neuropathic Pain
}

\author{
Shan-Xue Jin, ${ }^{\star}$ Zhi-Ye Zhuang, ${ }^{\star}$ Clifford J. Woolf, and Ru-Rong Ji \\ Neural Plasticity Research Group, Department of Anesthesia and Critical Care, Massachusetts General Hospital and Harvard Medical School, Boston, \\ Massachusetts 02129
}

\begin{abstract}
The possible involvement of p38 mitogen-activated protein kinase activation in spinal cord and dorsal root ganglion (DRG) cells in the development of peripheral neuropathic pain has been explored. Ligation of the L5 spinal nerve (SNL) on one side in adult rats produces an early onset and long-lasting mechanical allodynia. This lesion results in activation of p38 in the L5 segment of the spinal cord, most prominently in the ipsilateral dorsal horn, starting soon after the lesion $(<1 \mathrm{~d})$ and persisting for $>3$ weeks. The activated p38 in the spinal cord is restricted entirely to microglia; phospho-p38 colocalizes only with the microglial marker OX-42 and not with either the neuronal marker neuronal-specific nuclear protein or the astrocyte marker GFAP. In contrast, SNL induces a delayed ( $>3 \mathrm{~d})$ activation of p38 in the L5 DRG that occurs predominantly in neurons. Continuous injection of the p38 inhibitor 4-(4-fluorophenyl)-2-(4methylsulfonylphenyl)-5-(4-pyridyl)-1H-imidazole (SB203580) via the intrathecal route, starting before the SNL surgery, reduces SNLinduced mechanical allodynia from day 1 to day 10, with maximal effects at early time points. Post-treatment with SB203580 starting on day 1 or on day 10 after surgery also reduces established mechanical allodynia. Because the reduction in neuropathic pain by 38 inhibition occurs before the appearance of p38 activation in DRG neurons, p38 activation in spinal cord microglia is likely to have a substantial role in the earliest phase of neuropathic pain. Coactivation of $\mathrm{p} 38$ in DRG neurons and spinal microglia may contribute to later phases of neuropathic pain.
\end{abstract}

Key words: p38 MAPK; neuropathic pain; microglia; spinal cord; dorsal root ganglion; spinal nerve ligation

\section{Introduction}

Although pain hypersensitivity was originally thought to result exclusively from altered neuronal activity in the primary sensory and spinal cord neurons, there is evidence indicating that glial cells may also play a role in the pathogenesis of pain (Meller et al., 1994; Watkins et al., 1997, 2001a,b; DeLeo and Yezierski, 2001). Several cytokines that are released from glial cells produce pain hypersensitivity (DeLeo and Yezierski, 2001; Watkins et al., 2001a,b), and astrocytes and microglia are activated in the spinal cord after inflammation and nerve injury and in cancer models (Fu et al., 1999; Sweitzer et al., 1999; Winkelstein et al., 2001; Mantyh et al., 2002).

The mitogen-activated protein kinases (MAPKs) are a family of signaling molecules that transduce extracellular stimuli into intracellular responses in a wide variety of circumstances. The MAPK family includes extracellular signal-regulated kinase

\footnotetext{
Received Dec. 3, 2002; revised March 5, 2003; accepted March 5, 2003.

This work was supported by National Institutes of Health Grant R01NS 40698 to R.-R.J.

*S.-X.J. and Z.-Y.Z. contributed equally to this work.

Correspondence should be addressed to Dr. Ru-Rong Ji, Neural Plasticity Research Group, Department of Anesthesia and Critical Care, Massachusetts General Hospital, Harvard Medical School, 149 13th Street, Room 4309, Charlestown, MA 02129. E-mail: ji@helix.mgh.harvard.edu.

Copyright $\odot 2003$ Society for Neuroscience $\quad$ 0270-6474/03/234017-06\$15.00/0
}

(ERK), p38, c-Jun N-terminal kinase (JNK), and ERK5 (Widmann et al., 1999). ERK is involved both in cell proliferation and differentiation during development and in neuronal plasticity in the adult. p38 and JNK are stress-activated protein kinases and participate in injury responses and cell death (Widmann et al., 1999; Ji and Woolf, 2001). ERK and p38 both have distinct roles in generating pain sensitivity. Activation of ERK in dorsal root ganglion (DRG) and dorsal horn neurons contributes to the development and maintenance of pain hypersensitivity through transcription-dependent and -independent means (Ji et al., 1999, 2002a; Aley et al., 2001; Karim et al., 2001; Dai et al., 2002). p38 has been implicated in exaggerated pain states (Watkins et al., 2001b). CNI-1493, initially thought to be a monocyte synthesis inhibitor but more recently recognized to be a p38 inhibitor, has been shown to decrease both formalin-induced hyperalgesia and human immunodeficiency virus-1 glycoprotein 120-induced pain hypersensitivity (Watkins et al., 1997; Milligan et al., 2000, 2001). p38 is activated in DRG nociceptor neurons by peripheral inflammation and participates in the maintenance of inflammatory heat hyperalgesia by regulating protein but not mRNA levels of vanilloid receptor type 1 of the transient receptor potential channel family (TRPV1) (Ji et al., 2002b). Phospho-p38 (p-p38), the active form of $\mathrm{p} 38$, is present constitutively in non-neuronal 
cells in the spinal cord, and inflammation induces only a modest increase in p-p38 levels (Ji et al., 2002b). Here, we show that spinal nerve ligation (SNL), a widely used model for neuropathic pain (Kim and Chung, 1992), induces an early activation of p38 in spinal microglia and a later one in DRG neurons and contributes to the development of neuropathic pain.

Parts of this work have been published previously in abstract form (Jin et al., 2002).

\section{Materials and Methods}

Animals and surgery. Male adult Sprague Dawley rats (250-320 gm) were used under Massachusetts General Hospital Animal Care institutional guidelines. The rats were anesthetized with isoflurane $(2 \%)$. To produce an SNL, the L5 transverse process was removed to expose the L4 and L5 spinal nerves. The L5 spinal nerve was isolated carefully and ligated tightly with 6-0 silk thread (Kim and Chung, 1992). For intrathecal injection, a polyethylene-10 catheter was inserted into the rat's subarachnoid space through a small incision at the cisterna magna, and the tip of the catheter was implanted at the L4 spinal segmental level. Animals were allowed to recover for at least $2 \mathrm{~d}$ before SNL. The p38 inhibitor 4-(4-fluorophenyl)-2-(4-methylsulfonylphenyl)-5-(4-pyridyl)1H-imidazole (SB203580) (Calbiochem, La Jolla, CA) or vehicle (saline) was injected intrathecally $(10 \mu \mathrm{l})$ and flushed with $10 \mu \mathrm{l}$ of saline.

Western blots. Animals were killed quickly in a $\mathrm{CO}_{2}$ chamber. The L5 dorsal horns were removed rapidly and homogenized in an SDS sample buffer that contained a mixture of proteinase and phosphatase inhibitors (Ji et al., 2002a). The protein concentration of tissue lysates was determined with a BCA Protein Assay Kit (Pierce, Rockford, IL), and $30 \mu \mathrm{g}$ of protein was loaded in each lane. Protein samples were separated on SDSPAGE gel (4-15\% gradient gel; Bio-Rad, Hercules, CA) and transferred to polyvinylidene difluoride filters (Millipore, Bedford, MA). The filters were blocked with $5 \%$ milk in PBS with $0.1 \%$ Tween 20 for $1 \mathrm{hr}$ at room temperature (RT) and incubated over two nights at $4{ }^{\circ} \mathrm{C}$ with anti-p-p38 antibody (anti-rabbit, 1:1000, in 5\% BSA; Cell Signaling) or anti-total p38 antibody (anti-rabbit, 1:2000, in 5\% BSA; Cell Signaling). The blots were incubated for $1 \mathrm{hr}$ at RT with HRP-conjugated secondary antibody (Amersham Biosciences; 1:5000), developed in ECL solution (NEN, Boston, MA) for $1 \mathrm{~min}$, and exposed onto hyperfilms (Amersham Biosciences) for 3-30 min.

Immunohistochemistry. After defined survival times, control and injured rats were terminally anesthetized and perfused through the ascending aorta with saline, followed by $4 \%$ paraformaldehyde with $1.5 \%$ picric acid in $0.16 \mathrm{M}$ phosphate buffer, $\mathrm{pH} 7.2-7.4,4^{\circ} \mathrm{C}$. After perfusion, the L5 spinal cord segments and L5 DRGs were removed and postfixed in the same fixative for $3 \mathrm{hr}$ and then replaced with 15\% sucrose overnight. Transverse free-floating spinal sections $(30 \mu \mathrm{m})$ and DRG sections (15 $\mu \mathrm{m})$ were cut in a cryostat and processed for immunostaining with immunofluorescence (Ji et al., 2002a). All of the sections were blocked with $2 \%$ goat serum in $0.3 \%$ Triton $\mathrm{X}-100$ for $1 \mathrm{hr}$ at RT and incubated over two nights at $4^{\circ} \mathrm{C}$ with anti-p-p38 antibody (anti-rabbit, 1:400; Cell Signaling). The sections were then incubated for $1 \mathrm{hr}$ at RT with Cy3conjugated secondary antibody (1:300; Jackson ImmunoResearch, West Grove, PA). For double immunofluorescence, spinal sections were incubated with a mixture of polyclonal p-p38 and monoclonal neuronalspecific nuclear protein (NeuN) (neuronal marker, 1:5000; Chemicon, Temecula, CA), GFAP (astrocyte marker, 1:5000; Chemicon), and OX-42 (CD11b, microglia marker, 1:5000; Serotec, Indianapolis, IN) over two nights at $4^{\circ} \mathrm{C}$, followed by a mixture of FITC- and Cy3conjugated secondary antibodies for $1 \mathrm{hr}$ at RT. The stained sections were examined with a Nikon (Tokyo, Japan) fluorescence microscope, and images were captured with a CCD spot camera. The double-stained images were examined with Bio-Rad confocal microscopy. Some DRG sections were also immunostained with the ABC method (Ji et al., 1994).

Behavioral analysis. Animals were habituated to the testing environment daily for $2 \mathrm{~d}$ before baseline testing. All of the animals were placed on an elevated wire grid. For mechanical paw-withdrawal threshold, the plantar surface of the hindpaw was stimulated with a series of von Frey hairs. The threshold was taken as the lowest force that evoked a brisk withdrawal response (Ji et al., 2002a,b). To test the effect of the p38 inhibitor SB203580 on basal mechanical sensitivity, $10 \mu \mathrm{g}$ of SB203580 was injected intrathecally into noninjured rats, and the paw withdrawal thresholds were measured at $0.5,3$, and $24 \mathrm{hr}$ after the injection. For the pretreatment protocol, SB203580 $(2 \mu \mathrm{g})$ was injected intrathecally twice per day at 10 A.M. and 6 P.M. from day 0 to day 13 , and mechanical

a
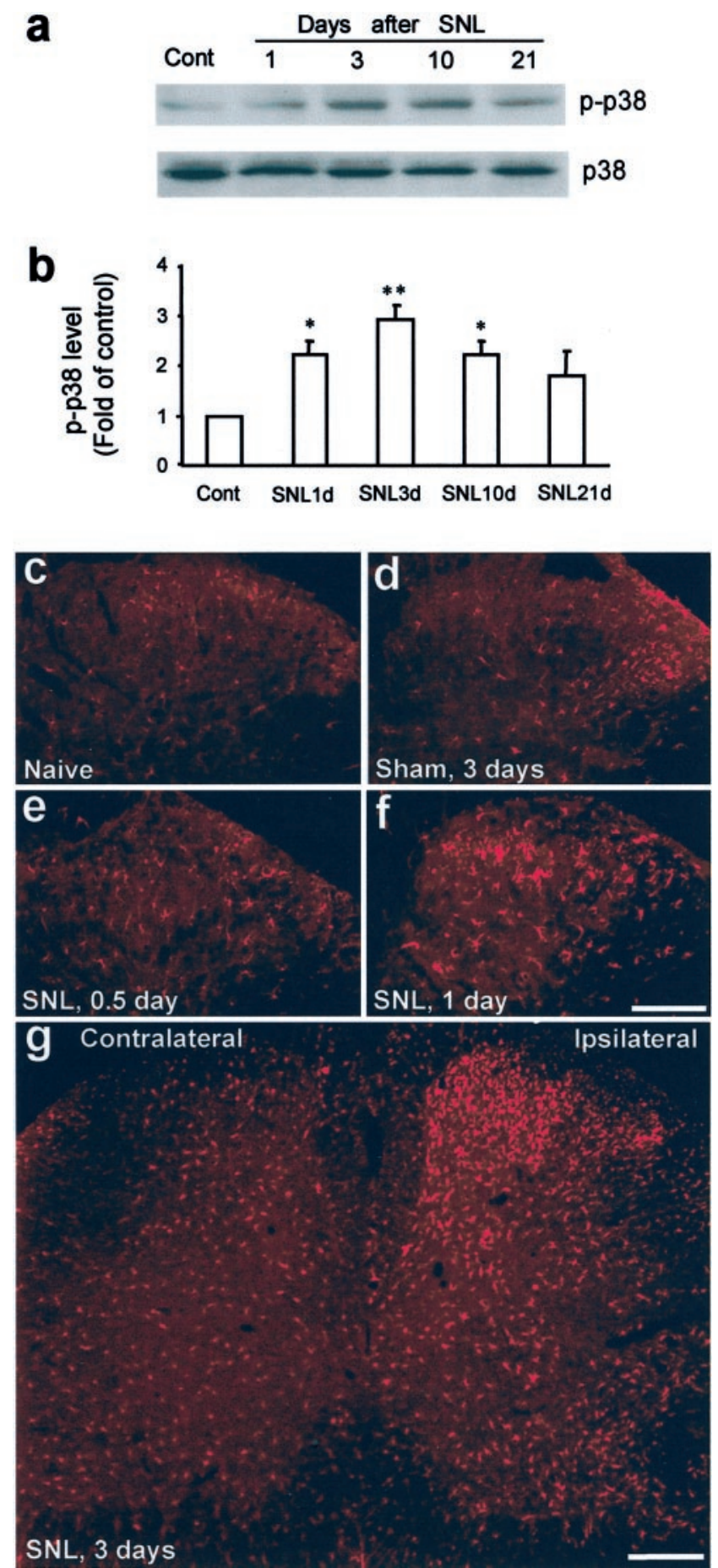

Figure 1. $a-g$, SNL induces p38 activation in the dorsal horn. $a, b$, Western blot analysis reveals rapid and persistent $\mathrm{p} 38$ activation in the $L 5$ dorsal horn after $L 5$ SNL. $b$, Quantification of a. p-p38 level is normalized against total p38 level. ${ }^{*} p<0.05$ and ${ }^{* *} p<0.01$ versus control; ANOVA ( $n=4$ or 5). c, $d, p$-p38 immunostaining in the dorsal horn of naive control rats $(c)$ and sham control rats $(d)$ at day 3. $e-g$, Immunohistochemistry indicates a gradual increase in the number of p-p38 immunoreactive cells in the ipsilateral spinal cord after SNL. Scale bars: $f, g$, $200 \mu \mathrm{m}$. Cont, Control. 

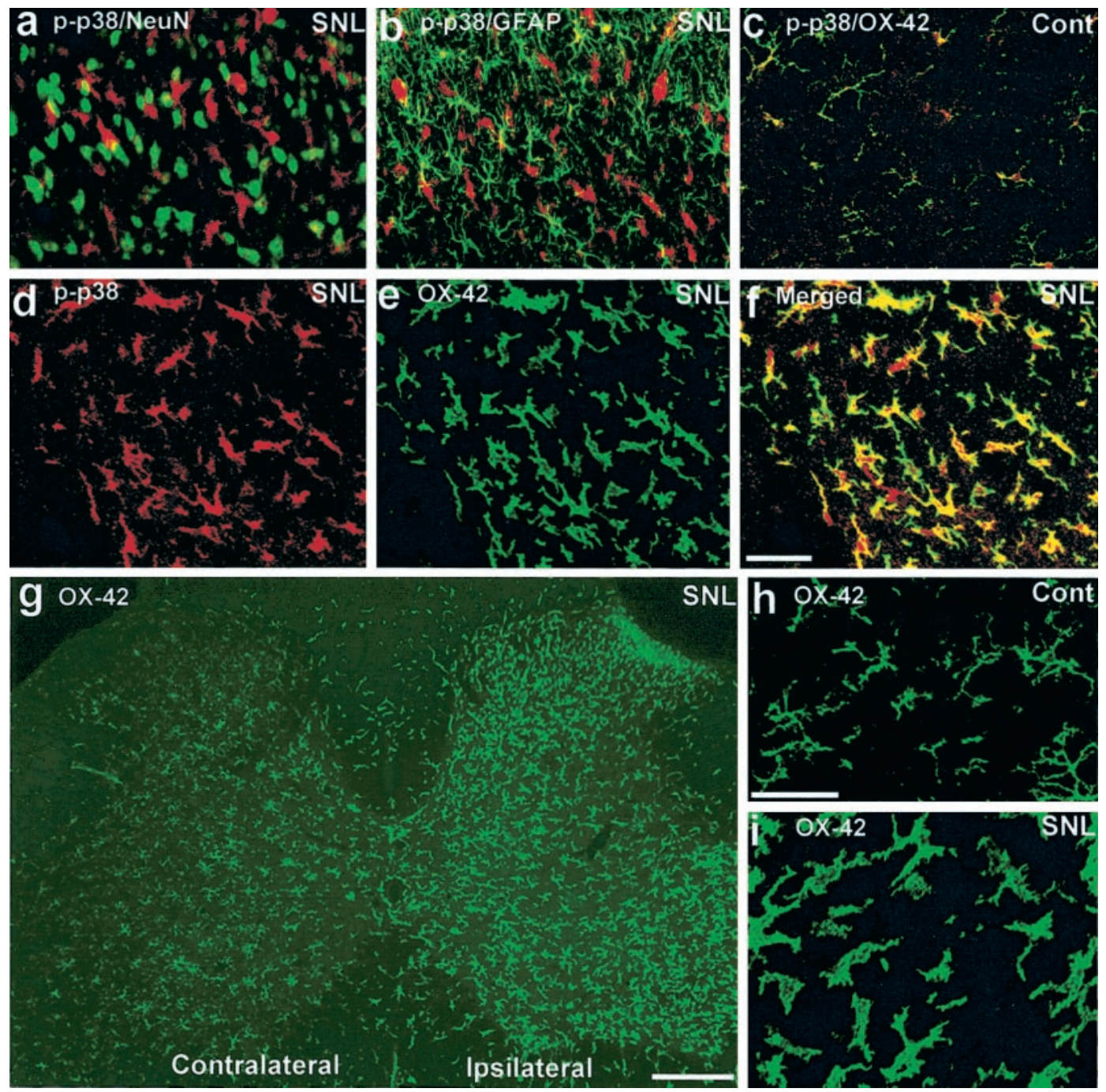

Figure 2. $a-i$, SNL induces p38 activation in the spinal microglia. $a-c$, Double immunofluorescence in the dorsal horn for p-p38 (red) and NeuN, a neuronal marker (green; a); GFAP, an astrocyte marker (green; $b$ ); and 0X-42, a microglia marker (green; $c$ ). Two images are merged in $a-c$. $a$ and $b$ were obtained from ipsilateral dorsal horn $3 \mathrm{~d}$ after $\mathrm{SNL}$, and $c$ was obtained from the contralateral dorsal horn as a control. $d-f$, Double immunofluorescence indicates a complete colocalization $(f)$ between p-p38 $(d)$ and $0 X-42(e)$ in the dorsal horn $3 d$ after SNL. $f, 0$ verlay of $d$ and $e . g-i, 0 X-42$ immunostaining in the spinal cord. $h, i$, High-magnification images showing the transformation of microglia from ramified shape to amoeboid shape $3 \mathrm{~d}$ after SNL. Scale bars: (in $f$ ) $a-f, 20 \mu \mathrm{m} ; g$, $200 \mu \mathrm{m}$; (in $h) h, i, 20 \mu \mathrm{m}$. Cont, Control.

allodynia was tested at 9 A.M. on days $1,3,5,7,10$, and 14 . For the post-treatment protocol, mechanical allodynia was tested at $0.5,3$, and $24 \mathrm{hr}$ after SB203580 injection (2 or $10 \mu \mathrm{g})$.

Quantification and statistics. For Western blots, the density of specific p-p38 bands was measured with a computer-assisted image analysis system (Adobe Systems, San Jose, CA) and normalized against total p38 level. For immunostaining in the DRG, every fifth section was picked from a series of consecutive DRG sections $(15 \mu \mathrm{m})$, and four sections were counted for each DRG and expressed as the percentage of total neuronal profiles (Ji et al., 1996). Three to five rats were included for each group for quantification of Western blot and immunohistochemistry results. A total of 6-11 rats per group were included for behavioral studies. Differences between groups were compared by Student's $t$ test or ANOVA followed by Fisher's PLSD post hoc analysis. The criterion for statistical significance was $p<0.05$.

\section{Results}

\section{p38 activation in the spinal cord}

An anti-p-p38 antibody was used to study changes in p38 activation. SNL induced a significant increase in p-p38 levels in the L5 dorsal horn, as detected by Western blots $\left(F_{(4,15)}=4.415\right.$; ANOVA; $p=0.0148)$. The increase was detectable at day 1 after surgery (2.2-fold; $p<0.05$; post hoc comparison), reached a peak at day 3 (2.9-fold; $p<0.01$; post hoc comparison), and was maintained (2.2-fold) for 3 weeks (Fig. 1 $a, b)$. The total nonphosphorylated p38 levels did not change after SNL (Fig. 1a). p-p38 immunohistochemistry showed a low basal constitutive expression in naive spinal cords (Fig. 1c). A slight increase in p-p38 levels occurred in the lateral dorsal horn of the lumbar spinal cord after sham surgery (exposure of the L5 spinal nerve without ligation) (Fig. 1d). p-p38 levels started to increase $12 \mathrm{hr}$ after SNL in the superficial dorsal horn (Fig. 1e). The increase in p-p38 levels became more obvious at $1 \mathrm{~d}$ (Fig. $1 f$ ). Three days after the SNL, a substantial increase in the number and intensity of p-p38immunoreactive (IR) cells was evident in the ipsilateral L5 spinal cord (Fig. 1g). The most prominent increase was found in the medial laminas I-IV of the dorsal horn, but the deep dorsal horn (laminas V and VI) and the ventral horn also showed an increase in p-p38-IR cells (Fig. 1g).

To identify the cell types that expressed p-p38 after SNL, we performed double immunostaining of p-p38 with several cellspecific markers: NeuN (neurons), GFAP (astrocytes), and 

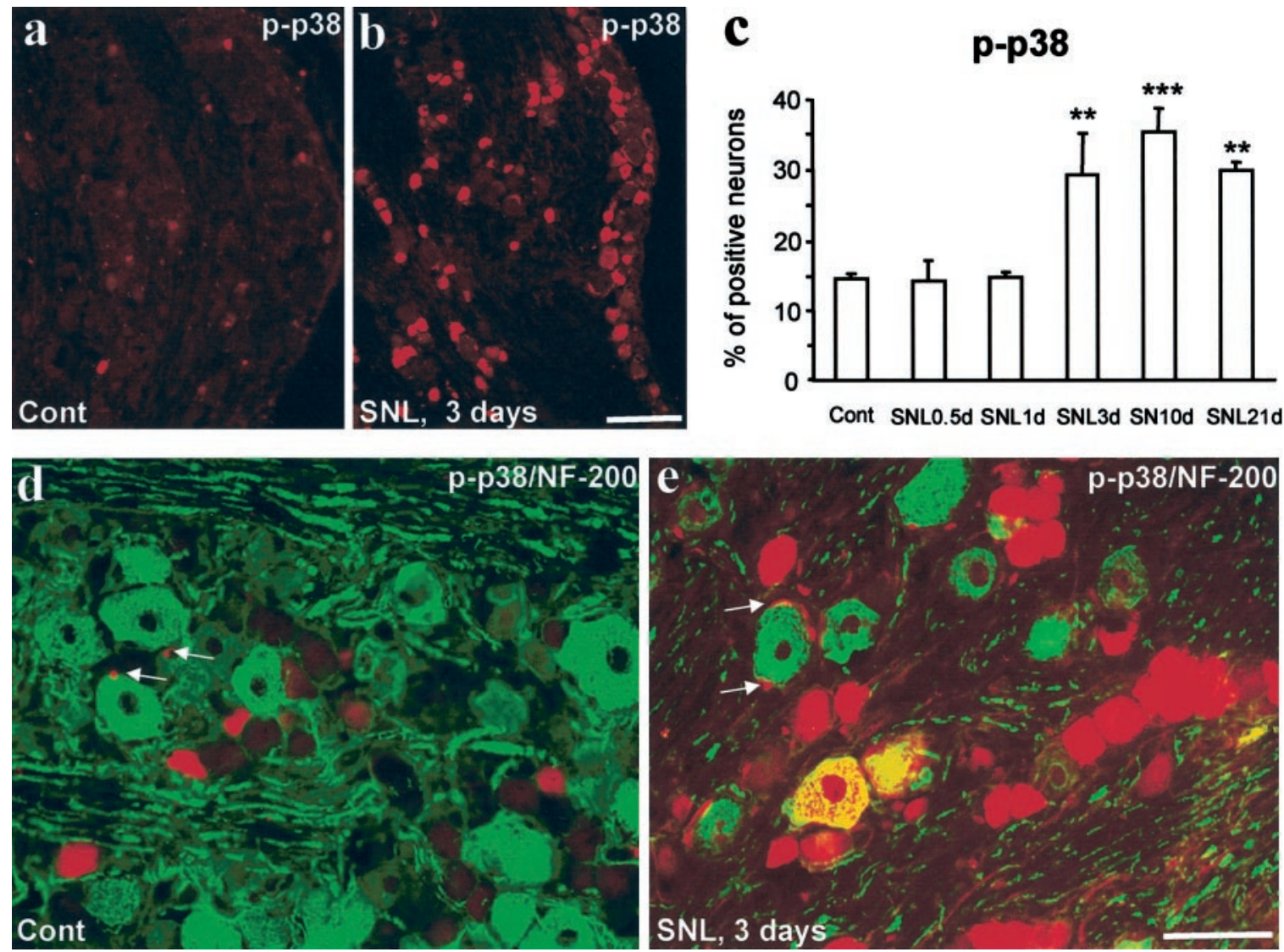

Figure 3. $a-e$, SNL induces p 38 activation in DRG neurons. $a-c$, Immunohistochemistry shows p-p38 staining in the L 5 DRG of naive control rats $(a)$ and SNL rats at $3 \mathrm{~d}(b)$.c, Quantification of $p$-p38 levels in the L5 DRG. ${ }^{* *} p<0.01$ and ${ }^{* * *} p<0.001$ (ANOVA) versus naive control; $n=3$. d, e, Double immunofluorescence shows colocalization of $p$-p38 with NF-200 in DRG neurons $3 \mathrm{~d}$ after SNL. Arrows indicate small satellite cells. Scale bars: (in $b) a, b, 100 \mu \mathrm{m}$; (in e) $d, e, 50 \mu \mathrm{m}$. Cont, Control.

OX-42 (CD-11b, microglia). p-p38 did not colocalize with either NeuN or GFAP (Fig. 2a,b). However, p-p38 completely colocalized with OX-42 in both control (Fig. $2 c$ ) and SNL (Fig. $2 d-f$ ) spinal cords. These results indicate that p38 is activated exclusively in microglia.

Microglial activation was also induced by SNL in the ipsilateral spinal cord, as indicated by an increase in the number and intensity of OX-42-IR cells (Fig. $2 g$ ). These cells were ramified in the spinal cord of control animals (Fig. $2 h$ ) but became amoeboid in shape after injury, a sign of microglial activation (Fig. 2i). SNL also induced activation of astrocytes in the ipsilateral spinal cord at day 3 , as indicated by increased GFAP expression (data not shown), but these cells did not express p-p38.

\section{p38 activation in the DRG}

SNL induced an increase in the percentage of p-p38-IR neurons in the L5 DRG $\left(F_{(5,12)}=9.334 ; p=0.0008\right)$. This increase was delayed, only reaching significance on day 3 ( $p<0.01$; post hoc comparison) (Fig. $3 a-c$ ), but lasted for $>3$ weeks ( $p<0.01$; post hoc comparison) (Fig. 3c). The increase in p-p38 in the DRG was found primarily in DRG neurons (Fig. 3d,e). There was also a slight increase in the number of p-p38-expressing satellite cells surrounding neurons in the DRG (Fig. 3d,e). Double staining of p-p38 with neurofilament-200 (NF-200), a marker for myelinated A-fibers, showed no colocalization in naive control DRGs, as reported previously (Ji et al., 2002b). Three days after SNL, some NF-200-labeled neurons started to express p-p38 (Fig. 3d,e).
These results indicate that SNL induces p38 activation in both Cand A-fiber DRG neurons.

\section{p38 activation and behavioral hypersensitivity}

We have demonstrated in a previous study that intrathecal infusion of SB203580 via an osmotic pump dose not change basal nociceptive behavior (Ji et al., 2002b). Here, we find that a single intrathecal injection of SB203580 $(10 \mu \mathrm{g})$ also had no effect on the mechanical threshold of naive animals. The paw-withdrawal thresholds at $0.5,3$, and $24 \mathrm{hr}$ after the injection were $92.3 \pm 21.8$, $109.3 \pm 25.5$, and $88.2 \pm 25.8 \%$ of the baseline values $\left(F_{(3,20)}=\right.$ 0.1564; ANOVA; $p=0.9243$ ).

SNL induced a mechanical allodynia that was present on day 1 after the surgery and was maintained for many weeks. To investigate the contribution of $\mathrm{p} 38$ activation to this altered behavior, we intrathecally administered the p38 inhibitor SB203580. First, to obtain a sustained inhibition of p38 over the time course of early development of neuropathic pain, we infused SB203580 (2 $\mu \mathrm{g})$ twice per day for 2 weeks, with the first injection administered 30 min before the SNL injury. This SB203580 infusion protocol significantly reduced SNL-induced mechanical allodynia from day 1 ( $p<0.05$; Student's $t$ test) to day 10 (Fig. $4 a$ ). The extent of the inhibition decreased gradually over the first week but was still significant after $10 \mathrm{~d}$ ( $p<0.05$; Student's $t$ test $)$ (Fig. 4a).

To test whether p38 inhibition has any role in established pain hypersensitivity after SNL, we applied a single injection of 

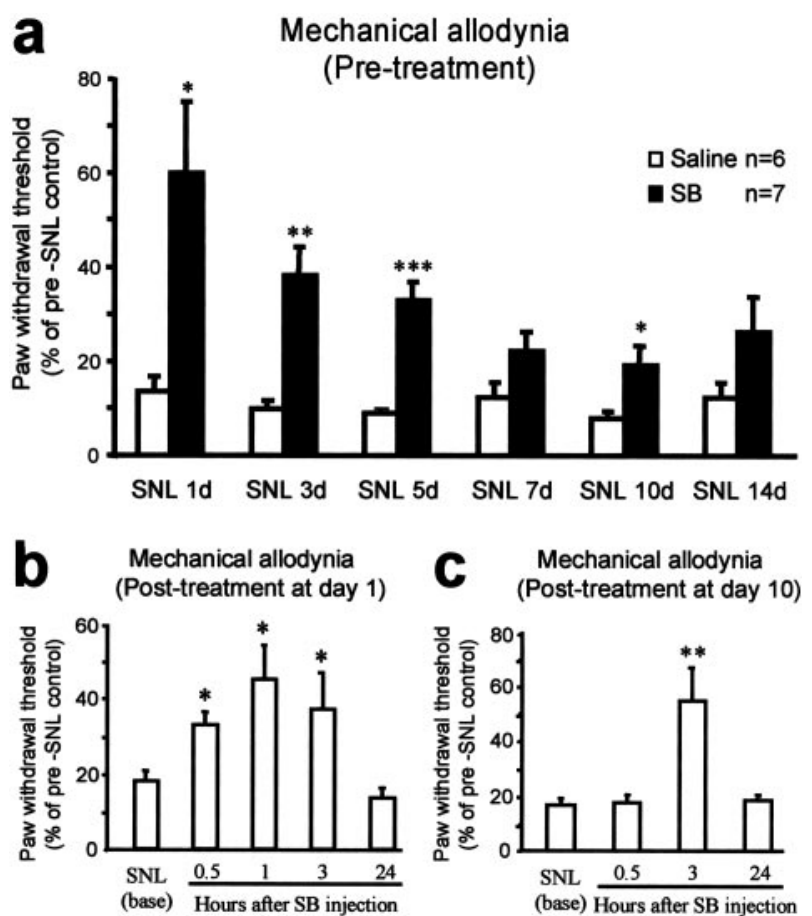
(Post-treatment at day 10)

Figure 4. $a-c, p 38$ activation contributes to neuropathic pain. $a$, Before treatment, a continuous infusion of the p38 inhibitor SB203580 (SB) partially prevents the development of mechanical allodynia. SB203580 (2 $\mu \mathrm{g})$ was administered intrathecally twice per day for 2 weeks, with the first injection $30 \mathrm{~min}$ before the SNL. The mechanical allodynia was tested in the morning before the daily SB203580 infusion. ${ }^{*} p<0.05 ;{ }^{* *} p<0.01$; ${ }^{* * *} p<0.001$; Student's $t$ test (compared with corresponding saline control). $b, c$, After treatment, a single injection of SB203580 (10 $\mu \mathrm{g})$ intrathecally decreases SNL-induced mechanical allodynia at both day $1(b)$ and day $10(c) .{ }^{*} p<0.05$ and ${ }^{* *} p<0.01$ (ANOVA) compared with SNL baseline. $n=7$ and 11 for mechanical test at day 1 and 10 , respectively.

SB203580 (10 $\mu \mathrm{g})$ intrathecally. This postsurgical treatment, administered at day 1 and day 10, reduced mechanical allodynia at both day $1\left(F_{(4,30)}=4.248 ; p=0.0077\right)$ (Fig. $\left.4 b\right)$ and day 10 $\left(\right.$ ANOVA; $F_{(3,40)}=7.740 ; p=0.0003$ ) (Fig. $4 c$ ). However, such a single injection of p38 inhibitor only produced a transient inhibition of mechanical allodynia that lasted a few hours. Post hoc comparisons indicated that SB203580 produced a significant inhibition at $3 \mathrm{hr}$ after injection $(p<0.05$ ) (Fig. $4 b, c)$ but not at 24 hr $(p>0.05)$ (Fig. 4b,c). This effect appeared to be dose dependent. A low dose of SB203580 $(2 \mu \mathrm{g})$ produced a moderate but insignificant inhibition of SNL-induced mechanical allodynia at day 10. The paw-withdrawal thresholds before and $0.5,3$, and 24 $\mathrm{hr}$ after the injection were $11.0 \pm 2.2,11.4 \pm 1.6,29.8 \pm 9.0$, and $7.8 \pm 2.7 \%$ of the baseline values, respectively $\left(F_{(3,21)}=2.818\right.$; ANOVA; $p=0.0639$ ).

\section{Discussion}

In the spinal cord, p38 is activated exclusively in microglia after SNL, a change that manifests $12-24 \mathrm{hr}$ after the injury, persists for several weeks, and coincides with the microglial activation that occurs after the lesion. This is in contrast to the increase in p-p38 levels in the DRG cells, which appears later (3d) and is located in neurons. Intrathecal injection of the p38 inhibitor SB203580 does not affect basal pain sensitivity but reduces pain hypersensitivity after SNL, with maximum benefit during the first few days after the injury. It appears that p38 is involved more in the development than in the maintenance of neuropathic pain. Because the dural membrane in rats extends onto the capsule of the DRG, intrathecal injection of a p38 inhibitor would affect cells in the DRG (Ji et al., 2002b) as well as those in the spinal cord. However, the effect of SB203580 treatment on day 1 after surgery is very likely to reflect an action only on microglial p38 in the spinal cord. p38 inhibition produced by treatment after day 3 may include an action on DRG neurons as well. The p38 inhibitor SB203580 does not inhibit the phosphorylation of p38 MAPK but rather binds to the ATP pocket in the enzyme, thereby inhibiting its activity (Koistinaho and Koistinaho, 2002), whereas CNI-1493 blocks the phosphorylation of p38 (Milligan et al., 2001).

Microglia are a source of multiple cytokines, including interleukin-1 $\beta$ (IL-1 $\beta$ ), IL-6, and tumor necrosis factor- $\alpha$ (Hanisch, 2002). These cytokines can contribute to different features of pathological pain, although their role within the spinal cord has not been explored fully (DeLeo and Yezierski, 2001; Watkins et al., 2001a,b). Microglia also express cyclooxygenase-2 (COX-2) and inducible nitric oxide synthase (iNOS), which leads to the synthesis of prostaglandin and nitric oxide, which can also enhance pain sensitivity (DeLeo and Yezierski, 2001; Watkins et al., 2001a,b; Koistinaho and Koistinaho, 2002). p38 activation appears to regulate the expression of cytokines, COX-2, and iNOS via transcriptional, post-transcriptional (mRNA stability), and translational (Widmann et al., 1999; Ji and Woolf, 2001; Koistinaho and Koistinaho, 2002) regulation. Activation of p38 in brain microglia has been found after brain ischemia (Koistinaho et al., 2002; Koistinaho and Koistinaho, 2002), but this is quite different from the activation found in response to injury of the peripheral nervous system (the spinal nerve). SNL will induce release of transmitters (glutamate and ATP), neuromodulators (substance $\mathrm{P}$, calcitonin gene-related peptide, and BDNF), and other signaling molecules such as chemokines from primary afferents as a result of both an immediate injury discharge and altered ectopic activity. This afferent activity may be responsible for activation of $\mathrm{p} 38$ in the spinal microglia. The p38 activation in response to SNL is widespread (present in dorsal and ventral horn); therefore, it is likely that it is a universal response to all injured afferents, including those with myelinated and unmyelinated axons and with low and high thresholds. The activation is, moreover, topographically organized, restricted to the general area of the central terminals of the injured spinal nerve, and is therefore very likely to reflect a spatially restricted local signal from the afferent central terminals. p38 activation can cause microglia activation in the brain (Tikka et al., 2001; Koistinaho et al., 2002); whether this is true for the spinal microglia needs to be investigated. The spatial distribution of activated microglia and p38 expression was almost identical.

We have shown recently that inflammation induces delayed and sustained p38 activation in DRG neurons via a retrograde signaling molecule, NGF. This activation mediates an upregulation of TRPV1 without changing TRPV1 mRNA levels (Ji et al., 2002 b). Because SNL also induces delayed p38 activation in DRG neurons, it is unlikely that this activation is a result of an immediate injury discharge and altered ectopic activity. Rather, p38 is likely to be activated by nerve inflammation or degeneration. p38 activation in DRG neurons may contribute to the increased expression of many proteins, such as BDNF, $\alpha 2 \delta$ calcium channel, and activating transcription factor 3 , that occur in injured DRG neurons (Zhou et al., 1999; Tsujino et al., 2000; Luo et al., 2001). Microarray studies have revealed that peripheral axonal injury produces changes in the expression of several hundred genes, and some of these may be regulated by p38 (Costigan et al., 2002; Xiao et al., 2002).

In conclusion, our results have shown p38 activation in a par- 
ticular type of glia, the microglia, in a neuropathic pain model. This activation plays a role in the early induction of neuropathic pain-like behavior. Later, p38 is activated in both spinal microglia and DRG neurons, which may cooperate to regulate the further development of neuropathic pain. Although glial cells have been implicated in a variety of acute and inflammatory pathological pains, we now provide evidence compatible with a role for microglia in the pathogenesis of neuropathic pain. Therefore, p38 inhibitors potentially can be used to treat not only inflammatory pain (Ji et al., 2002b) but also neuropathic pain.

\section{References}

Aley KO, Martin A, McMahon T, Mok J, Levine JD, Messing RO (2001) Nociceptor sensitization by extracellular signal-regulated kinases. J Neurosci 21:6933-6939.

Costigan M, Befort K, Karchewski L, Griffin RS, Da'Urso D, Allchorne A, Sitarski J, Mannion JW, Pratt RE, Woolf CJ (2002) Replicate high-density rat genome oligonucleotide microarrays reveal hundreds of regulated genes in the dorsal root ganglion after peripheral nerve injury. BMC Neurosci 3:16.

Dai Y, Iwata K, Fukuoka T, Kondo E, Tokunaga A, Yamanaka H, Tachibana T, Liu Y, Noguchi K (2002) Phosphorylation of extracellular signalregulated kinase in primary afferent neurons by noxious stimuli and its involvement in peripheral sensitization. J Neurosci 22:7737-7745.

DeLeo JA, Yezierski RP (2001) The role of neuroinflammation and neuroimmune activation in persistent pain. Pain 90:1-6.

Fu KY, Light AR, Matsushima GK, Maixner W (1999) Microglial reactions after subcutaneous formalin injection into the rat hind paw. Brain Res 825:59-67.

Hanisch UK (2002) Microglia as a source and target of cytokines. Glia 40:140-155.

Ji RR, Woolf CJ (2001) Neuronal plasticity and signal transduction in nociceptive neurons: implications for the initiation and maintenance of pathological pain. Neurobiol Dis 8:1-10.

Ji RR, Zhang X, Wiesenfeld-Hallin Z, Hokfelt T (1994) Expression of neuropeptide $\mathrm{Y}$ and neuropeptide $\mathrm{Y}(\mathrm{Y} 1)$ receptor $\mathrm{mRNA}$ in rat spinal cord and dorsal root ganglia following peripheral tissue inflammation. J Neurosci 14:6423-6434.

Ji RR, Zhang Q, Pettersson RF, Hokfelt T (1996) aFGF, bFGF and NGF differentially regulate neuropeptide expression in dorsal root ganglia after axotomy and induce autotomy. Regul Pept 66:179-189.

Ji RR, Baba H, Brenner GJ, Woolf CJ (1999) Nociceptive-specific activation of ERK in spinal neurons contributes to pain hypersensitivity. Nat Neurosci 2:1114-1119.

Ji RR, Befort K, Brenner GJ, Woolf CJ (2002a) ERK MAP kinase activation in superficial spinal cord neurons induces prodynorphin and NK-1 upregulation and contributes to persistent inflammatory pain hypersensitivity. J Neurosci 22:478-485.

Ji RR, Samad TA, Jin SX, Schmoll R, Woolf CJ (2002b) p38 MAPK activation by NGF in primary sensory neurons after inflammation increases TRPV1 levels and maintains heat hyperalgesia. Neuron 36:57-68.

Jin SX, Woolf CJ, Ji RR (2002) Activation of p38 MAPK in the dorsal root ganglion and spinal cord after spinal nerve ligation. Soc Neurosci Abstr 28:655.13.

Karim F, Wang CC, Gereau RW (2001) Metabotropic glutamate receptor subtypes 1 and 5 are activators of extracellular signal-regulated kinase signaling required for inflammatory pain in mice. J Neurosci 21:3771-3779.

Kim SH, Chung JM (1992) An experimental model for peripheral neuropathy produced by segmental spinal nerve ligation in the rat. Pain 50:355-363.
Koistinaho M, Koistinaho J (2002) Role of p38 and p44/42 mitogenactivated protein kinases in microglia. Glia 40:175-183.

Koistinaho M, Kettunen MI, Goldsteins G, Keinanen R, Salminen A, Ort M, Bures J, Liu D, Kauppinen RA, Higgins LS, Koistinaho J (2002) $\beta$-Amyloid precursor protein transgenic mice that harbor diffuse $\mathrm{A} \beta$ deposits but do not form plaques show increased ischemic vulnerability: role of inflammation. Proc Natl Acad Sci USA 99:1610-1615.

Luo ZD, Chaplan SR, Higuera ES, Sorkin LS, Stauderman KA, Williams ME, Yaksh TL (2001) Upregulation of dorsal root ganglion $\alpha 2 \delta$ calcium channel subunit and its correlation with allodynia in spinal nerve-injured rats. J Neurosci 21:1868-1875.

Mantyh PW, Clohisy DR, Koltzenburg M, Hunt SP (2002) Molecular mechanisms of cancer pain. Nat Rev Cancer 2:201-209.

Meller ST, Dykstra C, Grzybycki D, Murphy S, Gebhart GF (1994) The possible role of glia in nociceptive processing and hyperalgesia in the spinal cord of the rat. Neuropharmacology 33:1471-1478.

Milligan ED, Mehmert KK, Hinde JL, Harvey LO, Martin D, Tracey KJ, Maier SF, Watkins LR (2000) Thermal hyperalgesia and mechanical allodynia produced by intrathecal administration of the human immunodeficiency virus-1 (HIV-1) envelope glycoprotein, gp120. Brain Res 861:105-116.

Milligan ED, O'Connor KA, Armstrong CB, Hansen MK, Martin D, Tracey KJ, Maier SF, Watkins LR (2001) Systemic administration of CNI-1493, a p38 mitogen-activated protein kinase inhibitor, blocks intrathecal human immunodeficiency virus-1 gp120-induced enhanced pain states in rats. J Pain 2:326-333.

Sweitzer SM, Colburn RW, Rutkowski M, DeLeo JA (1999) Acute peripheral inflammation induces moderate glial activation and spinal IL-1 $\beta$ expression that correlates with pain behavior in the rat. Brain Res 829:209-221.

Tikka T, Fiebich BL, Goldsteins G, Keinanen R, Koistinaho J (2001) Minocycline, a tetracycline derivative, is neuroprotective against excitotoxicity by inhibiting activation and proliferation of microglia. J Neurosci 21:2580-2588.

Tsujino H, Kondo E, Fukuoka T, Dai Y, Tokunaga A, Miki K, Yonenobu K, Ochi T, Noguchi K (2000) Activating transcription factor 3 (ATF3) induction by axotomy in sensory and motoneurons: a novel neuronal marker of nerve injury. Mol Cell Neurosci 15:170-182.

Watkins LR, Martin D, Ulrich P, Tracey KJ, Maier SF (1997) Evidence for the involvement of spinal cord glia in subcutaneous formalin induced hyperalgesia in the rat. Pain 71:225-235.

Watkins LR, Milligan ED, Maier SF (2001a) Glial activation: a driving force for pathological pain. Trends Neurosci 24:450-455.

Watkins LR, Milligan ED, Maier SF (2001b) Spinal cord glia: new players in pain. Pain 93:201-205.

Widmann C, Gibson S, Jarpe MB, Johnson GL (1999) Mitogen-activated protein kinase: conservation of a three-kinase module from yeast to human. Physiol Rev 79:143-180.

Winkelstein BA, Rutkowski MD, Sweitzer SM, Pahl JL, DeLeo JA (2001) Nerve injury proximal or distal to the DRG induces similar spinal glial activation and selective cytokine expression but differential behavioral responses to pharmacologic treatment. J Comp Neurol 439:127-139.

Xiao HS, Huang QH, Zhang FX, Bao L, Lu YJ, Guo C, Yang L, Huang WJ, Fu G, Xu SH, Cheng XP, Yan Q, Zhu ZD, Zhang X, Chen Z, Han ZG, Zhang $X$ (2002) Identification of gene expression profile of dorsal root ganglion in the rat peripheral axotomy model of neuropathic pain. Proc Natl Acad Sci USA 99:8360-8365.

Zhou XF, Chie ET, Deng YS, Zhong JH, Xue Q, Rush RA, Xian CJ (1999) Injured primary sensory neurons switch phenotype for brain-derived neurotrophic factor in the rat. Neuroscience 92:841-853. 